\title{
Retinal Vein Occlusion: Current Treatment
}

\author{
Rosangela Lattanzio ${ }^{\mathrm{a}} \quad$ Ana Torres Gimeno $^{\mathrm{b}}$ Maurizio Battaglia Parodi ${ }^{\mathrm{a}}$ \\ Francesco Bandello ${ }^{a}$ \\ a Department of Ophthalmology, University Vita-Salute, Scientific Institute San Raffaele, Milan, Italy; \\ ${ }^{b}$ Department of Ophthalmology, Hospital Dr Peset, Valencia, Spain
}

\section{Key Words}

Retinal vein occlusion $\cdot$ Laser treatment $\cdot$ Intravitreal

injection - Antiangiogenic drug $\cdot$ Ranibizumab ·

Bevacizumab · Pegaptanib sodium $\cdot$ Vascular endothelial

growth factor trap $\cdot$ Steroids

\begin{abstract}
Retinal vein occlusion (RVO) is a pathology noted for more than 150 years. Although a lot has been written on the matter, it is still a frequent condition with multifactorial etiopathogenesis with many unclear aspects. The RVO pathogenesis has varied systemic and local implications that make it difficult to elaborate treatment guidelines. The management of the patient with RVO is very complex and a multidisciplinary approach is required in order to identify and correct the associated risk factors. Laser therapy remains the gold standard in RVO, but only modest functional improvement has been shown in branch retinal occlusion forms. Multicenter studies of intravitreal drugs present them as an option to combine with laser. Anti-vascular endothelial growth factor, corticosteroids and sustained-release implants are the future weapons to stop disease progression and get a better visual outcome. Consequently, it is useful to clarify some aspects of the pathology that allow a better patient management.

Copyright $\odot 2010$ S. Karger AG, Basel
\end{abstract}

\section{Introduction}

Retinal vein occlusion (RVO) is the second most common retinal vascular disorder after diabetic retinopathy and is a frequent cause of vision loss and even blindness [1-3]. Depending on the location of the obstruction, the RVOs can be divided into branch retinal vein occlusion (BRVO) or central retinal vein occlusion (CRVO). In BRVO, the obstruction is located in one of the branches of the central vein, affecting only part of the posterior pole and the portion of the peripheral retina drained by the occluded branch. In CRVO, it is located in the central vein, at the level of the optic nerve, so most of the retina is affected [4]. Symptoms, pathogenesis, risk factors and treatment are different for BRVO and CRVO. The purpose of this review is to summarize the current treatments of RVO, emphasizing evidence-based ones.

\section{Clinical Manifestations}

Vision is similarly variably decreased depending on the amount of retinal ischemia and edema. Patients with BRVO usually complain of a sudden painless decrease in vision or a visual field defect. Patients with CRVO, however, usually present with sudden, unilateral, painless loss

\section{KARGER}

Fax +4161306 1234 E-Mail karger@karger.ch www.karger.com
Francesco Bandello, MD, FEBO

Department of Ophthalmology, University Vita-Salute

Scientific Institute San Raffaele, Via Olgettina 60

IT-20132 Milan (Italy)

Tel. +39 022643 2648, Fax +39 022643 3643, E-Mail bandello.francesco@ hsr.it 
of vision. The degree of vision loss depends on the extent of retinal involvement and whether the macula is affected. Some patients may even have normal visual acuity (VA), especially if the macula is spared [5]. Although the prevalence of BRVO $(0.6-1.6 \%)$ is greater than that of CRVO $(0.1-0.4 \%)[1,2]$, CRVO is a disease that affects both anatomy and visual function more adversely than BRVO [6].

\section{Classification}

Both BRVO and CRVO can be subdivided into two types: ischemic (if more than 10 disk areas of capillary nonperfusion are noted on fluorescein angiography) and nonischemic (if fewer than 10 disk areas of retinal capillary nonperfusion are identified). Ischemic RVO is associated with a significant loss of VA at presentation and a poor prognosis, with $20 / 200$ or worse in $90 \%$ of patients, suggesting that the damage is substantial and, most often, irreversible. Nonischemic RVO is associated with a more positive outcome, with $60 \%$ of patients recovering to $20 / 30$ or better [5]. In addition, $16 \%$ of RVOs with perfusion can progress to ischemia in 4 months. During the next 32 months of follow-up, an additional 19\% of eyes can convert to ischemia for a total of $34 \%$ after 3 years. However, the development of nonperfusion or ischemia is most rapid in the first 4 months and progresses continuously throughout the entire duration of follow-up [7]. Visual complications associated with RVO include vitreous hemorrhage, macular edema, macular ischemia and neovascularization. Twenty percent of cases of CRVO develop iris neovascularization, usually by $6-7$ months after onset. But neovascular glaucoma develops in only $8 \%$ of CRVOs overall, in $80 \%$ of ischemic forms and $1 \%$ of those with nonischemic disease [8].

\section{Pathogenesis}

The pathogenesis is multifactorial and still unclear. The classic risk factors related to RVO are age, smoke, diabetes, hypertension and hyperlipidemia, which are more common in patients with BRVO $[9,10]$. Open-angle glaucoma or other conditions inducing increased intraocular pressure (IOP) are established local predisposing factors [11]. However, there are other risk factors that are related to hemostasis, such as hyperhomocysteinemia; these are more commonly related to CRVO $[9,12,13]$.
The close association of RVO with systemic vascular disease emphasizes the need to investigate cardiovascular risk factors in patients with RVO. Evaluation of a new patient with RVO must include a screen for hypertension, diabetes and lipid abnormalities because RVO may be the presentation of significant vascular morbidity. In younger patients, most of whom are otherwise healthy, the exact pathogenesis and risk factors of RVO are still poorly understood. However, when tests for common cardiovascular risk factors for RVO are negative, evaluation for potential coagulation disorders may be indicated, particularly in young patients and in patients with bilateral RVO, a history of previous thromboses or a family history of thrombosis [5].

\section{Treatment}

The current treatment options of RVO intend to minimize the damage, because there is no proven treatment that can improve vision loss in the long term. Therapy wants to prevent further visual loss and its complications, such as macular edema, ischemia or neovascularization.

\section{Medical Treatment}

There are several medical options, but most are not evidence-based. The use of isovolemic hemodilution requires careful patient selection and should be avoided in patients with concurrent cardiovascular, renal or pulmonary disease. Unfortunately, as a significant number of patients with vein occlusion have cardiovascular comorbidity, and the benefits are limited, it is not recommended [3]. Another option is thrombolysis with tissue plasminogen activator (tPA). If administrated intravitreally, it shows outcomes that are similar to the natural history of RVO [14]. In the ROLF study, intravenous tPA improved the visual prognosis in patients with acute CRVO when compared with hemodilution. But there was no conclusive evidence for BRVO. Another interesting observation of this study was that thrombolysis was not associated with a lower risk of ocular neovascularization, indicating that the mechanisms involved in this process occur at an early stage [15]. Besides, Hayreh's [16] experience indicates that anticoagulants and antiplatelet agents are also contraindicated in CRVO, as they are not only of no therapeutic value but can be harmful. 


\section{Surgery}

Chorioretinal anastomosis pretends to permanently bypass the site of obstruction to venous outflow in CRVO, by creating an anastomotic connection between the retinal and the choroidal veins. It can be performed using surgery or argon laser. Both techniques have shown encouraging results $[17,18]$, but also a high rate of side effects. With surgery, cataract, vitreous cavity hemorrhage, and retinal detachment may occur [18], while laser-induced anastomosis can induce the development of neovascular membranes at the anastomotic site [17] (successfully treated with intravitreal bevacizumab [19]).

Vascular surgery pretends to restore blood flow. One option would be vitreous surgery with cannulation of tPA into the retinal vein, achieving an improvement in VA of 3 lines or more in $54 \%$ of the patients [20]. Some surgeons have also reported successful results with radial optic neurotomy (RON), but complications of the procedure have been reported. Opremcak et al. [21-23] reported anatomic resolution of CRVO in $92-95 \%$ of 180 patients following RON with associated improvement in VA. Binder et al. [24] found clinically relevant improvements on a long-term follow-up with RON; patients with nonischemic CRVO may respond more favorably than patients with ischemic CRVO. But when comparing both procedures, Yamamoto et al. [25] concluded that although there was no significant difference in surgical outcomes between the two procedures, the therapies with tPA cannulation or RON alone were inadequate, because an additional treatment was necessary. However, Friberg et al. [26] found the biomechanical effect of RON negligible, and that it was unlikely to be a procedure that could mechanically ameliorate the clinical sequelae of a central vein occlusion. Besides, arteriovenous crossing sheathotomy for BRVO or optic nerve sheath decompression for CRVO could be other options. But there is no evidence that supports any therapeutic benefit from these procedures in eyes with vein occlusion [3]. On the other hand, the pars plana vitrectomy with internal limiting membrane peeling studies showed different results. While anatomic improvement was always achieved with surgery, a significant improvement in best corrected visual acuity (BCVA) was not always present [27-29].

\section{Laser Treatment}

Although various medical and surgical treatments have been attempted with different success rates, laser therapy remains the gold standard in RVO, according to the results of the CRVO and BRVO study groups $[1,2,30]$.

Panretinal photocoagulation (PRP) should be considered in CRVO when anterior segment neovascularization is clinically detected and confirmed by fluorescein angiography, to prevent progression to neovascular glaucoma [1]. It is not recommended prophylactically, because PRP does not totally prevent iris or angle neovascularization, and prompt regression of iris or angle neovascularization response to PRP is more likely to occur in eyes that have not been treated previously. So the CRVO group recommends careful observation with frequent follow-up examinations in the early months (including undilated slit lamp examination of the iris and gonioscopy) and just prompt PRP of eyes in which anterior segment neovascularization develops [7, 31].

Peripheral scatter laser photocoagulation of ischemic retina is recommended in BRVO in the presence of retinal and disk neovascularization to reduce the occurrence of vitreous hemorrhage [32].

Macular grid photocoagulation is an effective treatment to improve vision, but only for BRVO macular edema [2-30]. In CRVO, even if the treatment clearly reduces angiographic evidence of macular edema, macular grid photocoagulation results in no VA improvement [33]. Current guidelines recommend it in BRVO when vision loss due to macular edema persists for more than 3 months without spontaneous improvement and VA is within the range of 20/40 to 20/200 [2], although the results achieved are modest.

\section{Intravitreal Treatment}

\section{Anti-Vascular Endothelial Growth Factor Drugs}

Vascular endothelial growth factor (VEGF) is a major regulator of angiogenesis and vascular permeability in the eye for physiologic as well as pathologic processes [34]. It is demonstrated that the aqueous humor levels of VEGF and interleukin-6, which also increases vascular permeability, are significantly elevated in CRVO patients, above all in patients with retinal ischemia. In addition, the aqueous humor levels are significantly correlated with the severity of macular edema and had an inverse correlation with VA. These findings suggest that both VEGF and interleukin-6 may contribute to the development and progression of macular edema in patients with CRVO [35-37]. Campochiaro et al. [36] found an inverse correlation between VEGF levels and VA. Moreover, Funk et al. [38] demonstrated that monthly treatment 
with anti-VEGF reduced VEGF and interleukin-1 levels to undetectable values and below physiologic levels, but there was no action on other cytokines and growth factors. So another treatment option is the use of anti-VEGF agents injected intravitreally. The most studied are bevacizumab $\left(\right.$ Avastin $\left.^{\circledR}\right)$, ranibizumab (Lucentis ${ }^{\circledR}$ ) and pegaptanib sodium (Macugen ${ }^{\circledR}$ ).

\section{Bevacizumab}

There have been several studies with bevacizumab and RVO, retrospective or prospective, all showing improvements in VA and optical coherence tomography (OCT) outcomes, but also short-term efficacy and high recurrence rate. The dosage varies between 1 and $2.5 \mathrm{mg}$, there are no different outcomes [39-48]. The Pan-American Collaborative Retina Study group concluded that intravitreal injections of bevacizumab at doses up to $2.5 \mathrm{mg}$ were more effective in improving VA and reducing macular edema at 6 months (compared to $1.25 \mathrm{mg}$ ), but the study had no control group [44]. By contrast, no statistically significant differences were found between the doses, when the group presented the results at 24 months [49]. In addition, Ach et al. [50] found that CRVO patients who benefit from therapy were significantly younger and had lower central retinal thickness at baseline, while BRVO patients showed no predictive factors for effectiveness of bevacizumab therapy. Furthermore, intravitreal bevacizumab has also been successfully used in RVO for reversing iris neovascularization that causes neovascular glaucoma [51].

\section{Ranibizumab}

With ranibizumab, Pieramici et al. [52] designed a study following the scheme of the PIER Study, i.e. the first 3 injections monthly and then after 6 and 9 months, if needed (persistent macular edema). They found that ranibizumab is generally well tolerated and may improve BCVA and decrease central retinal thickness in OCT. But the efficacy was lost after the loading phase, so an interval of 3 months between injections may be too long. In addition, Spaide et al. [53] and Rouvas et al. [54] demonstrated in two prospective studies that the patients with RVO have an improvement in VA, but with a mean of 7.4-8.5 injections in 1 year of follow-up.

Nowadays two phase III multicenter, prospective clinical trials are under way, assessing the safety, tolerability and efficacy of intravitreal ranibizumab injections in the treatment of macular edema secondary to BRVO and CRVO [55]. They are called BRAVO (study of the efficacy and safety of ranibizumab injection compared with sham in patients with macular edema due to BRVO) and CRUISE (study of the efficacy and safety of ranibizumab injection compared with sham in patients with macular edema due to CRVO). During the first 6 months, the patients monthly received either 0.3 or $0.5 \mathrm{mg}$ of ranibizumab or sham injection. During the second 6-month period, the patients were evaluated monthly and treated on an as-needed basis; meanwhile, patients in the sham group received $0.5 \mathrm{mg}$ ranibizumab. In addition, in the BRAVO study, rescue laser therapy was performed if criteria were met. For the first 6 months, results are available. Regarding efficacy, at the primary endpoint (mean change from baseline BCVA at month 6), there is a rapid and sustained improvement in BCVA in patients with macular edema due to BRVO or CRVO. They show a statistically significant number of patients who gained $\geq 15$ letters from baseline at month 6 , in the study group compared to the control group, as well as a change from baseline central foveal thickness over time to month 6 . In the BRVO group, more patients in the sham group received rescue grid laser, compared with the 0.3 or $0.5 \mathrm{mg}$ ranibizumab groups. Besides, intravitreal ranibizumab seems to have a safety profile consistent with previous phase III trials, and low rates of ocular and nonocular safety events $[56,57]$. Moreover, these two trials demonstrate that the duration of the disease does not matter for taking the decision of treating. Treated patients did always better than sham-treated patients. Therefore, treatment for RVO can also be delayed by 3 months [58].

\section{Pegaptanib Sodium}

The pegaptanib sodium is a selective anti-VEGF and it is still not well studied in RVO. Bennet [59] performed a pilot study where Macugen treatment achieved a decrease in macular thickness and an improvement in VA and retinal perfusion. But this study had enrolled only 7 patients with 6 months of follow-up and it had no control group. On the other hand, Wroblewski et al. [60] conducted a study where subjects with BRVO were randomized 3:1 to intravitreal injections of pegaptanib 0.3 or $1 \mathrm{mg}$ at baseline and at weeks 6 and 12 with subsequent injections at 6 -week intervals at the discretion of the investigator until week 48 . He also found improvements in VA and macular thickness in this study with a 54-week follow-up. Therefore, the authors consider that intravitreal pegaptanib offers a promising alternative for macular edema secondary to BRVO.

\section{VEGF Trap}

The VEGF trap is another novel anti-VEGF agent. It is essentially a small fully human, soluble VEGF receptor 
that acts as a decoy receptor binding-free VEGF [34]. The VEGF trap eye is currently under evaluation in two phase III studies on CRVO (GALILEO and COPERNICUS Studies) with 6-monthly injections of drug or sham-controlled injections.

\section{Anti-VEGF Use Limits}

Anti-VEGFs seem to be a safe and effective treatment for RVO in terms of VA and OCT results. They are also useful to reduce ischemic progression and to manage complications, such as neovascular glaucoma [61]. There are some prognostic factors for better outcome, such as better initial VA, no foveal hemorrhages, no macular ischemia, detection of VA gain after first injection, young age and final central retinal thickness $[45,48,62,63]$. But there are limits in efficacy, need for multiple injections, rebound effect of macular edema and nonresponders. In fact, there are no studies of long-term efficacy, even when it is known that the efficacy is lost after 3 consecutive injections (the loading phase) [48]. Donati et al. [unpubl. data, 2009] affirm that it is better if associated with grid laser, but we wait for results of other studies to clarify this point. Second, most of the patients needed repeated injections to achieve good results, depending on the different studies [47, 48, 53, 54]; the Pan-American Collaborative Retina Study group showed these high rates of injections in 24 months [48]. Third, there is no defined long-term therapeutic scheme and it is also not known when to start the treatment. Funk et al. [38] found reduced VEGF levels in long-term RVO, so there would be a benefit of early intervention. Fourth, although there is an initial reduction of the central retinal thickness, it is followed by a rebound effect of the macular edema, maybe caused by an upregulation of the VEGF receptors [52]. Fifth, another important limit is the still high percentage of patients that have no VA improvement with the treatment; according to Hoeh et al. [62], one third of the CRVO/BRVO patients. In addition, Park and Ahn [64] found that these nonresponders had higher aqueous levels of VEGF and were associated with ischemic forms.

In addition, in the era of anti-VEGF therapies, the effects of long-term VEGF inhibition are still unclear [65]. Bevacizumab, when used intravenously, is associated with an increased risk of arterial and venous thromboembolism and hypertension. While used intravitreally, the systemic absorption is minimal and the risk of cardiovascular disease is not elevated. However, a trend has been observed towards a higher risk of stroke among patients with a history of heart disease [60]. After all, current research may focus on ways of increasing the dura- bility of effect, reducing side effects and facilitating delivery of these drugs [34].

\section{Corticosteroids}

Another intravitreal treatment option are corticosteroids, which inhibit not only VEGF but also various proinflammatory mediators that contribute to the pathogenesis of RVO. Commercially available corticosteroid options include a variety of formulations, with durations of action that range from a few weeks to more than a year [66].

\section{Triamcinolone}

Since 2002, several case reports have shown results of intravitreal triamcinolone (IVTA) in RVO. Even with different dosages (from 4 to $25 \mathrm{mg}$ ), the response appears short lived, so more than one injection is needed [67-72]. Besides, the efficacy is better after the first injection than after the next ones, perhaps because of a tachyphylactic effect [67-70]. The risks of steroid administration must also be considered, such as raised IOP, infection, cataract progression or retinal detachment [67-72]. On the other hand, the macular edema reduction seems less effective for ischemic forms, not only in case report studies [69] but also in prospective, comparative studies [71].

The SCORE (Standard care vs. COrticosteroid for REtinal vein occlusion) study consists of 2 multicenter, randomized, phase III clinical trials comparing the safety and efficacy of standard care with IVTA in either a 1or a 4-mg dose for vision loss associated with macular edema secondary to CRVO or BRVO. In the CRVO trial, standard care therapy is observation. Retreatments are considered for persistent or new macular edema at 4-month intervals. The results at the primary endpoint (at month 12) show a gain in the VA letter score of $\geq 15$ from baseline, but with a mean number of 2.0-2.2 injections $[73,74]$.

The SCORE study report 5 (CRVO) showed that both triamcinolone groups were superior to observation with respect to VA. The visual benefit of IVTA was demonstrated as early as 4 months and continued to 24 months; although there was less power at this point, the benefit appeared to persist. However, in all 3 groups (1 mg IVTA, 4 mg IVTA or observation), there was a reduction of central retinal thickness from baseline to 24 months. Therefore, the visual benefit of IVTA may be due not only to macular edema decrease, but also to other effects, such as anti-inflammatory or neuroprotective effects. The study report 5 also evidenced the superior safety profile of the 1-mg dose compared with the 4-mg dose, particularly 
with respect to glaucoma and cataract, rendering it the preferred dose in CRVO [73].

The results on the SCORE study report 6 (BRVO) showed no significant differences in VA among the 3 treatment groups ( $1 \mathrm{mg}$ IVTA, $4 \mathrm{mg}$ IVTA or grid laser, being the standard of care) at the primary outcome visit (12 months). However, after 12 months and through month 36, the mean improvement in the VA letter score was better in the laser group. On the other hand, in all 3 groups, there was a reduction of central retinal thickness from baseline to 12 months. But after month 12 and through month 36 , the laser group demonstrated a better reduction in central retinal thickness from baseline. Finally, the laser group had a safety profile superior to both IVTA groups, according to the need for intraocular pressure-lowering medications and cataract formation [74].

In the studies of Tao et al. [75] and Hou et al. [76], comparing intravitreal bevacizumab and IVTA in longstanding nonischemic CRVO and BRVO, respectively, both drugs were associated with a comparable gain in VA. However, the reduction in CRVO macular edema was more marked in the triamcinolone group and the potential complications of triamcinolone (IOP elevation or cataract formation) makes bevacizumab more adapted to the treatment [75], while in the study of Hou et al. [76], the reduction of BRVO macular edema (except 3-month follow-up) was similar and with minor complications during 1 year in both groups.

\section{Combined Therapies with Triamcinolone}

Furthermore, combined therapies may be a good option. The combination of IVTA with grid laser photocoagulation has been proposed, obtaining positive outcomes [77-79]. On the other hand, the combined treatment with IVTA and intravitreal bevacizumab has been tested $[80,81]$. This combined treatment improved structural outcome in patients with RVO, according to Ehrlich et al. [81]. But this combination of IVTA and bevacizumab offered no advantage over previously published results with intravitreal bevacizumab alone for improving vision at 6 months [81].

IVTA can also be combined with surgery. Opremcak et al. [82] found RON combined with ITVA (RON/IVTA) a technically feasible procedure. But the clinical resolution and the improved visual function noted was similar to RON alone. Moreover, the RON/IVTA group was associated with a higher incidence of elevated IOP and endophthalmitis. Uemura et al. [83] also found no benefit in the use of intraoperative IVTA acetonide, when comparing it with vitrectomy alone. By contrast, Ma et al. [84] found that 25-gauge vitrectomy with triamcinolone-assisted internal limiting membrane peeling was generally effective in reducing macular edema and improving BCVA for chronic cystoid macular edema in BRVO for at least 7 months.

\section{Dexamethasone}

Another very interesting steroid is dexamethasone, but it has quite a short intravitreal half-life, so an intravitreal drug delivery system has been developed in order to maintain useful intravitreal levels. It is called DEX implant (OZURDEX, Allergan, Inc., Irvine, Calif.) and it is a biodegradable, injectable dexamethasone implant. The implant can be inserted into the vitreous cavity using a 22-gauge applicator, whose safety and effectiveness has been proven [85]. Two identical, 6-month, phase III, multicenter, masked, randomized, sham-controlled, clinical trials have been performed to asses the safety and efficacy of the intravitreal dexamethasone implant $(0.7$ and $0.35 \mathrm{mg}$ ) in macular edema associated with BRVO or CRVO (with 6-month open-label extension). After a sinlge administration, the time to achieve a $\geq 15$-letter improvement in BCVA (main outcome measures) was significantly less in both DEX implant groups compared to sham ( $p<0.001)$. Mean BCVA improvement was greater in both DEX implant groups compared to sham at days $30-180$ ( $\mathrm{p} \leq 0.006$ ). The percentage of eyes with $\geq 15$-letter BCVA improvement was significantly higher in both DEX implant groups than sham at days 30 to 90 ( $\mathrm{p} \leq 0.001$ ), but not day 180. Improvements in BCVA with DEX implant were seen in patients with BRVO and in patients with CRVO, although the patterns of response differ. The percentage of DEX implant-treated eyes with transiently increased IOP (to $\geq 25 \mathrm{~mm} \mathrm{Hg}$ ) peaked at $16 \%$ at day 60 and was not different from sham at day 180 . There was no significant difference in the development/ surgery of cataract between groups. Therefore, in patients with ME associated with BRVO or CRVO, DEX implant is a well-tolerated treatment that produced significantly greater and more rapid improvements in vision than did sham treatment [86].

Other Sustained-Release Implants

Other sustained-release implants have been tested for RVO. One example is the Verisome drug delivery technology. IBI-20089 is a novel drug product based on IBI's proprietary Verisome drug delivery platform technology with different doses of triamcinolone. The drug delivery system degrades as the active agent is released over the intended time duration. IBI-20089 is designed to last up 
to 1 year with a single intravitreal injection. A phase 1 multicenter study using it in patients with chronic cystoid edema due to RVO has been completed. They studied the safety and tolerability of IBI-20089. In addition, they compared two different doses $(6.9 \mathrm{mg}$ triamcinolone in $25 \mu \mathrm{l}$ and $13.8 \mathrm{mg}$ triamcinolone in $50 \mu \mathrm{l})$. This 12 -month study showed a good tolerance and a reduction in central retinal thickness in OCT. Besides, the larger dose was more effective than the smaller dose [87]. Another example is Retisert, a fluocinolone acetonide implant. It is currently in use for noninfectious posterior uveitis, where it has shown a significant reduction in recurrence rate and improvement in VA for approximately 3 years after implant [88]. In addition, it provides inflammatory control and reduces the dependence on systemic immunosuppression $[89,90]$. It has also been tested in patients with macular edema secondary to CRVO, achieving an improvement in VA and a reduction of the macular edema at 12 months [91]. But the implanted eyes had higher incidences of IOP elevation and cataracts [88, 90, 91].

\section{Conclusions}

The currently recommended treatment of RVO consists of identifying and managing cardiovascular risk factors and retinal laser therapy. But there are no updated clinical guidelines. The intravitreal injections turned out to be promising in recent clinical trials and appear to be an additional therapeutic option. However, there are still many unclear points, such as the number of injections, the correct time to start, the long-term efficacy or the specific moment to finish them.

There are some interesting areas for further research: first, if earlier treatment is associated with better outcomes; second, better assessment of efficacy and prognostic factors; third, importance of other factors, apart from VEGF, that can impact on the RVO and the possibility of blocking them. There are still many patients with visual loss, so there is a need for large well-designed prospective randomized controlled trials with a long-term follow-up of new drugs or combination therapies.

\section{References}

1 Central Vein Occlusion Study Group: Baseline and early natural history report. Arch Ophthalmol 1993;111:1087-1095.

$\checkmark 2$ Branch Vein Occlusion Study Group: Argon laser photocoagulation for macular edema in branch vein occlusion. Am J Ophthalmol 1984;98:271-282.

$\checkmark 3$ Shahid H, Hossain P, Amoaku WM: The management of retinal vein occlusion: is interventional ophthalmology the way forward? Br J Ophthalmol 2006;90:627-639.

4 Rehak J, Rehak M: Branch retinal vein occlusion: pathogenesis, visual prognosis and treatment modalities. Curr Eye Res 2008;33: 111-131.

$\checkmark 5$ Yau JW, Lee P, Wong TY, Best J, Jenkins A: Retinal vein occlusion: an approach to diagnosis, systemic risk factors and management. Intern Med J 2008;38:904-910.

$\checkmark 6$ Ip MS, Oden NL, Scott IU, VanVeldhuisen PC, Blodi BA, Figueroa M, Antoszyk A, Elman M, SCORE Study Report 3: Study design and baseline characteristics. Ophthalmology 2009;116:1770-1777.

-7 The Central Vein Occlusion Study Group: Natural history and clinical management of central retinal vein occlusion. Arch Ophthalmol 1997;115:486-491.

8 Zegarra H, Gutman FA, Conforto J: The natural course of central retinal vein occlusion. Ophthalmology 1979;86:1931-1942.
-9 Turello M, Pasca S, Daminato R, Dello Russo P, Giacomello R, Venturelli U, Barillari G: Retinal vein occlusion: evaluation of 'classic' and 'emerging' risk factors and treatment. J Thromb Thrombolysis 2010;29:459-464.

10 Williamson TH: Central retinal vein occlusion: what's the story? Br J Ophthalmol 1997; 81:698-704.

11 David R, Zangwill L, Badarna M, Yassur Y: Epidemiology of retinal vein occlusion and its association with glaucoma and increased intraocular pressure. Ophthalmologica 1988;197:69-74.

12 Lattanzio R, Sampietro F, Ramoni A, Fattorini A, Brancato R, D’Angelo A: Moderate hyperhomocysteinemia and early-onset central retinal vein occlusion. Retina 2006;26: 65-70.

-13 McGimpsey SJ, Woodside JV, Cardwell C, Cahill M, Chakrawarthy U: Homocysteine, methylenetetrahydrofolate reductase C677T polymorphism, and risk of retinal vein occlusion: a meta-analysis. Ophthalmology 2009;116:1778-1787

14 Glacet-Bernard A, Kuhn D, Vine AK, Oubraham H, Coscas G, Soubrane G: Treatment of recent onset central vein occlusion with intravitreal tissue plasminogen activator: a pilot study. Br J Ophthalmol 2000;84:609613.
15 Hattenbach L, Friedrich Arndt C, Lerche R, Scharrer I, Baatz H, Margaron F, Richard G, Behrens-Baumann W, Ohrloff C: Retinal vein occlusion and low-dose fibrinolytic therapy (ROLF). A prospective, randomized, controlled multicenter study of low-dose recombinant tissue plasminogen activator versus hemodilution in retinal vein occlusion. Retina 2009;29:932-940.

16 Hayreh SS: Venous occlusive disease: management 25 years ago. Retina 2006;26:51-62.

17 Fekrat S, Goldberg MF, Finkelstein D: Laserinduced chorioretinal venous anastomosis for nonischemic central or branch retinal vein occlusion. Arch Ophthalmol 1998;116: 43-52.

18 Mirshahi A, Roohipoor R, Lashay A, Mohammadi SF, Mansouri MR: Surgical induction of chorioretinal venous anastomosis in ischemic central retinal vein occlusion: a non-randomised controlled clinical trial. $\mathrm{Br}$ J Ophthalmol 2005;89:64-69.

19 Fong KC, Barry C, McAllister IL: Intravitreal bevacizumab (Avastin) as a treatment of the neovascular complications of laser-induced chorioretinal anastomosis for nonischemic central retinal vein occlusion. Clin Experiment Ophthalmol 2009;37:485-489.

20 Weiss JN, Bynoe LA: Injection of tissue plasminogen activator into a branch retinal vein in eyes with central retinal vein occlusion. Ophthalmology 2001;108:2249-2257. 
-21 Opremcak EM, Rehmar AJ, Ridenour CD, Kurz DE: Radial optic neurotomy for central retinal vein occlusion: 117 consecutive cases. Retina 2006;26:297-305.

22 Opremcak EM: Radial optic neurotomy. Ophthalmology 2008;115:1638-1639.

23 Opremcak EM: Radial optic neurotomy for CRVO. Retina Today 2009;4:67-69.

-24 Binder S, Aggerman T, Brunner S: Longterm effects of radial optic neurotomy for central retinal vein occlusion consecutive interventional case series. Graefes Arch Clin Exp Ophthalmol 2007;245:1447-1452.

-25 Yamamoto T, Kamei M, Sakaguchi H, Oshima Y, Ikuno Y, Gomi F, Ohji M, Tano Y: Comparison of surgical treatments for central retinal vein occlusion: RON versus cannulation of tissue plasminogen activator into the retinal vein. Retina 2009;29:1167-1174.

-26 Friberg TR, Smolinski P, Hill S, Kurup SK: Biomechanical assessment of radial optic neurotomy. Ophthalmology 2008;115:174180 .

27 DeCroos FC, Shuler RK Jr, Stinnett S, Fekrat S: Pars plana vitrectomy, internal limiting membrane peeling, and panretinal endophotocoagulation for macular edema secondary to central retinal vein occlusion. Am J Ophthalmol 2009;147:627-633.

28 Arai M, Yamamoto S, Mitamura Y, Sato E, Suguwara T, Mizunoya S: Efficacy of vitrectomy and internal limiting membrane removal for macular edema associated with branch retinal vein occlusion. Ophthalmologica 2009;223:172-176.

-29 Raszewska-Steglinska M, Gozdek P, Cisiecki S, Michalewska Z, Micalewski J, Nawrocki J: Pars plana vitrectomy with ILM peeling for macular edema secondary to retinal vein occlusion. Eur J Ophthalmol 2009;19:10551062.

30 Parodi MB, Bandello F: Branch retinal vein occlusion: classification and treatment. Ophthalmologica 2009;223:298-301.

- 31 The Central Vein Occlusion Study Group: A randomized clinical trial of early panretinal photocoagulation for ischemic central vein occlusion. Ophthalmology 1995;102:14341444.

-32 The Branch Vein Occlusion Study Group: Argon laser scatter photocoagulation for prevention of neovascularization and vitreous hemorrhage in branch vein occlusion. A randomized clinical trial. Arch Ophthalmol 1986;104:34-41.

- 33 The Central Vein Occlusion Study Group: Evaluation of grid pattern photocoagulation for macular edema in central vein occlusion. Ophthalmology 1995;102:1425-1433.

34 Pieramici DJ, Rabena MD: Anti-VEGF therapy: comparison of current and future agents. Eye 2008;22;1330-1336.
35 Noma H, Funutsu H, Mimura T, Harino S, Sone T, Hori S: Increase of vascular endothelial growth factor and interleukin- 6 in the aqueous humour of patients with macular edema and central retinal vein occlusion. Acta Ophthalmol DOI: 10.1111/j.17553768.2009.01524.x.

36 Campochiaro PA, Hafiz G, Shah SM, Nguyen QD, Ying H, Do DV, Quinlan E, ZimmerGaller I, Haller JA, Solomon SD, Sung JU, Hadi Y, Janjua KA, Jawed N, Choy DF, Arron JR: Ranibizumab for macular edema due to retinal vein occlusions: implication of VEGF as a critical stimulator. Mol Ther 2008;16: 791-799.

37 Noma H, Minamoto A, Funatsu H, Tsukamoto H, Nakano K, Yamashita H, Mishima HK: Intravitreal levels of vascular endothelial growth factor and interleukin- 6 are correlated with macular edema in branch retinal vein occlusion. Graefes Arch Clin Exp Ophthalmol 2006;244:309-315.

38 Funk M, Kriechbaum K, Prager F, Benesch T, Georgopoulos M, Zlabinger GJ, SchmidtErfurth U: Intraocular concentrations of growth factor and cytokines in retinal vein occlusion and the effect of therapy with bevacizumab. Invest Ophthalmol Vis Sci 2009; 50:1025-1032.

39 Iturralde D, Spaide RF, Meyerle CB, Klancnik JM, Yannuzzi LA, Fisher YL, Sorenson J, Slakter JS, Freund KB, Cooney M, Fine HF: Intravitreal bevacizumab (Avastin) treatment of macular edema in central retinal vein occlusion. A short-term study. Retina 2006;26:279-284.

40 Costa RA, Jorge R, Calucci D, Melo LA Jr, Cardillo JA, Scott IU: Intravitreal bevacizumab (Avastin) for central and retinal vein occlusions. IBeVo study. Retina 2007;27:141149.

41 Fish GE: Intravitreous bevacizumab in the treatment of macular edema from branch retinal vein occlusion and hemisphere retinal vein occlusion (an AOS thesis). Trans Am Ophthalmol Soc 2008;106:276-300.

42 Rabena MD, Pieramici DJ, Castellarin AA, Nasir MA, Avery RL: Intravitreal bevacizumab (Avastin) in the treatment of macular edema secondary to branch retinal vein occlusion. Retina 2007;27:419-425.

43 Badalá F: The treatment of branch retinal vein occlusion with bevacizumab. Curr Opin Ophthalmol 2008;19:234-238.

-44 Wu L, Arevalo JF, Roca JA, Maia M, Berrocal MH, Rodriguez FJ, Evans T, Costa RA, Cardillo J: Comparison of two doses of intravitreal bevacizumab (Avastin) for treatment of macular edema secondary to branch retinal vein occlusion: results from the Pan-American Collaborative Retina Study (PACORES) Group at 6 months of follow-up. Retina 2008 28:212-219.
45 Chung EJ, Hong YT, Lee SC, Kwon OW, Koh HJ: Prognostic factors for visual outcome after intravitreal bevacizumab for macular edema due to branch retinal vein occlusion. Graefes Arch Clin Exp Ophthalmol 2008; 246:1241-1247.

-46 Ahmadi AA, Chou JY, Banashkevich A, Ma PE, Maberley DA: The effects of intravitreals bevacizumab on patients with macular edema secondary to branch retinal vein occlusion. Can J Ophthalmol 2009;44:154-159.

47 Prager F, Michels S, Kriechbaum K, Georgopoulos M, Funk M, Geitzenauer W, Polak $\mathrm{K}$, Schmidt-Erfurth U: Intravitreal bevacizumab (Avastin) for macular oedema secondary to retinal vein occlusion: 12-month results of a prospective clinical trial. $\mathrm{Br} \mathrm{J}$ Ophthalmol 2009;93:452-456.

48 Kondo M, Kondo N, Ito Y, Achi S, Kikuchi M, Yasuma TR, Ota I, Miyake K, Terasaki H: Intravitreal injection of bevacizumab for macular edema secondary to branch retinal vein occlusion. Results after 12 months and multiple regression analysis. Retina 2000;29: 1242-1248.

49 Wu L, Arevalo JF, Berrocal MH, Maia M, Roca JA, Morales-Cantón V, Alezzandrini AA, Díaz-Llopis MJ: Comparison of two doses of intravitreal bevacizumab as primary treatment of macular edema secondary to branch retinal vein occlusions: results from the Pan-American Collaborative Retina Study (PACORES) Group at 24 months. Retina 2009;29:1396-1403.

50 Ach T, Hoeh AE, Schaal KB, Scheuerle AF, Dithmar S: Predictive factors for changes in macular edema in intravitreal bevacizumab therapy of retinal vein occlusion. Graefes Arch Clin Exp Ophthalmol 2010;248:155159.

-51 Douat J, Auriol S, Mahieu-Durringer L, Ancèle E, Pagot-Mathis V, Mathis A: Intravitreal bevacizumab for treatment of neovascular glaucoma. Report of 20 cases. J Fr Ophtalmol 2009;32:652-663.

- 52 Pieramici DJ, Rabena M, Castellarin AA, Nasir M, See R, Norton T, Sanchez A, Risard S, Avery RL: Ranibizumab for the treatment of macular edema associated with perfused central retinal vein occlusion. Ophthalmology 2008;115:e47-e54.

-53 Spaide RF, Chang LK, Klancnik JM, Yannuzzi LA, Sorenson J, Slakter JS, Freund KB, Klein R: Prospective study of ranibizumab as a treatment of decreased visual acuity secondary to central retinal vein occlusion. Am J Ophthalmol 2009;147:298-306.

54 Rouvas A, Petrou P, Vergados I, Pechtasides D, Liarakos V, Mitsopoulou M, Ladas I: Intravitreal ranibizumab (Lucentis) for treatment of central retinal vein occlusion: a prospective study. Graefes Arch Clin Exp Ophthalmol 2009;247:1609-1616.

55 Pieramici DJ: Intravitreal ranibizumab for treatment of macular edema secondary to retinal vein occlusion. Retina Today 2009;4: 44-46. 
56 Campochiaro PA, Heier JS, Feiner L, Gray S, Saroj N, Rundle AC, Murahashi WY, Rubio RG, BRAVO Investigators: Ranibizumab for macular edema following branch retinal vein occlusion six-month primary end point results of a phase III study. Ophthalmology 2010;117:1102-1112.

57 Brown DM, Campochiaro PA, Singh RP, Li Z, Saroj N, Rundle AC, Rubio RG, Murahashi WY, CRUISE Investigators: Ranibizumab for macular edema following central retinal vein occlusion six-month primary end point results of a phase III study. Ophthalmology 2010;117:1124-1133.

58 Brown DM: Clinical implications of the BRAVO and CRUISE trials. Retina Today 2010;5:38-40.

59 Bennet MD: Pegaptanib for the treatment of ischemic retinopathy in patients with diabetes and retinal vascular occlusive disorders. Retina Today 2009;4:63-66.

60 Wroblewski JJ, Wells JA 3rd, Gonzales CR: Pegaptanib sodium for macular edema secondary to branch retinal vein occlusion. Am J Ophthalmol 2010;149:147-154

-61 Hasanreisoglu M, Weinberger D, Mimouni K, Luski M, Bourla D, Kramer M, Robinson A, Axer-Siegel R: Intravitreal bevacizumab as an adjunct treatment for neovascular glaucoma. Eur J Ophthalmol 2009;19:607612.

-62 Hoeh AE, Ach T, Schaal KB, Scheuerle AF, Dithmar S: Long-term follow-up of OCTguided bevacizumab treatment of macular edema due to retinal vein occlusion. Graefes Arch Clin Exp Ophthalmol 2009;247:16351641.

63 Kriechbaum K, Michels S, Prager F, Georgopoulos M, Funk M, Geitzenauer W, Schmidt-Erfurth U: Intravitreal Avastin for macular oedema secondary to retinal vein occlusion: a prospective study. Br J Ophthalmol 2008;92:518-522.

64 Park SP, Ahn JK: Changes of aqueous vascular endothelial growth factor and pigment epithelium-derived factor following intravitreal bevacizumab for macular oedema secondary to branch retinal vein occlusion. Clin Experiment Ophthalmol 2009;37:490495.

65 Wong TY: Age-related macular degeneration and cardiovascular disease in the era of antivascular endothelial growth factor therapies. Am J Ophthalmol 2009;148:327-329.

66 Lee SS, Hughes PM, Robinson MR: Recent advances in drug delivery systems for treating ocular complications of systemic diseases. Curr Opin Ophthalmol 2009;20:511-519.

67 Greenberg PB, Martidis A, Rogers AH, Duker JS, Reichel E: Intravitreal triamcinolone acetonide for macular oedema due to central retinal vein occlusion. Br J Ophthalmol 2002;86:247-248.
68 Ip MS, Kumar KS: Intravitreous triamcinolone acetonide as treatment for macular edema from central retinal vein occlusion. Arch Ophthalmol 2002;120:1217-1219.

69 Jonas JB, Kreissig I, Degenring RF: Intravitreal triamcinolone acetonide as treatment of macular edema in central retinal vein occlusion. Graefes Arch Clin Exp Ophthalmol 2002;240:782-783.

70 Jonas JB, Akkoyun I, Kampetter B, Kreissig I, Degenring RF: Branch retinal vein occlusion treated by intravitreal triamcinolone acetonide. Eye 2005;19:65-71.

71 Gewaily D, Greenberg PB: Intravitreal steroid versus observation for macular edema secondary to central retinal vein occlusion (review). Cochrane Database Syst Rev DOI: 10.1002/14651858.CD007324.pub2.

72 Scott IU, Ip MS: Update on the SCORE Study. Retina Today 2009;4:48-49.

73 The SCORE Study Research Group: A randomized trial comparing the efficacy and safety of intravitreal triamcinolone with observation to treat vision loss associated with macular edema secondary to central retinal vein occlusion (SCORE) study report 5. Arch Ophthalmol 2009;127:1101-1114.

74 The SCORE Study Research Group: A randomized trial comparing the efficacy and safety of intravitreal triamcinolone with standard care to treat vision loss associated with macular edema secondary to branch retinal vein occlusion: the standard care vs corticosteroid for retinal vein occlusion (SCORE) study report 6. Arch Ophthalmol 2009;127:1115-1128.

75 Tao Y, Hou J, Jiang YR, Li XX, Jonas JB: Intravitreal bevacizumab vs triamcinolone acetonide for macular oedema due to central retinal vein occlusion. Eye 2010;24:810-815.

76 Hou J, Tau Y, Jiang Y, Li XX, Gao L: Intravitreal bevacizumab vs triamcinolone acetonide for macular edema due to branch retinal vein occlusion. Chin Med J 2009;122:26953699.

$>77$ Riese J, Loukopoulos V, Meier C, Timmermann M, Gerding $\mathrm{H}$ : Combined intravitreal triamcinolone injection and laser photocoagulation in eyes with persistent macular edema after branch retinal vein occlusion. Graefes Arch Clin Exp Ophthalmol 2008; 246:1671-1676.

78 Cakir M, Dogan M, Bayraktar Z, Bayraktar S, Acar N, Altan T, Kapran Z, Yilmaz OF: Efficacy of intravitreal triamcinolone for the treatment of macular edema secondary to branch retinal vein occlusion in eyes with and without grid laser photocoagulation. Retina 2008;28:465-472.

79 Parodi MB, Iacono P, Ravalico G: Intravitreal triamcinolone acetonide combined with subthreshold grid laser treatment for macular oedema in branch retinal vein occlusion: a pilot study. Br J Ophthalmol 2008;92:10461050.
80 Ekdawi NS, Bakri SJ: Intravitreal triamcinolone and bevacizumab combination therapy for macular edema due to central retinal vein occlusion refractory to either treatment alone. Eye 2007;21:1128-1130.

81 Ehrlich R, Ciulla TA, Moss AM, Harris A: Combined treatment of intravitreal bevacizumab and intravitreal triamcinolone in patients with retinal vein occlusion: 6 months of follow-up. Graefes Arch Clin Exp Ophthalmol 2010;248:375-380.

-82 Opremcak AM, Rehmar AJ, Ridenour CD, Kurz DE, Borkowski LM: Radial optic neurotomy with adjunctive intraocular triamcinolone for central retinal vein occlusion: 63 cases. Retina 2006;26:306-313.

83 Uemura A, Yamamoto S, Sato E, Sugawara T, Mitamura Y, Mizunoya S: Vitrectomy alone versus vitrectomy with simultaneous intravitreal injection of triamcinolone for macular edema associated with branch retinal vein occlusion. Ophthalmic Surg Lasers Imaging 2009;40:6-12.

84 Ma J, Yao K, Zhang Z, Tang X: 25-Gauge vitrectomy and triamcinolone acetonide-assisted internal limiting membrane peeling for chronic cystoid macular edema associated with branch retinal vein occlusion. Retina 2008;28:947-956.

-85 Haller JA, Dugel P, Weinberg DV, Chou C, Whitcup SM: Evaluation of safety and performance of an applicator for a novel intravitreal dexamethasone drug delivery system for the treatment of macular edema. Retina 2009;29:46-51.

-86 Haller JA, Bandello F, Belfort R, Blumenkranz M, Gillies M, Heier J, Lowenstein A, Yoon YH, Jacques ML, Jiao J, Li XY, Whitcup SM, OZURDEX GENEVA Study Group: Randomized, sham-controlled trial of dexamethasone intravitreal implant in patients with macular edema due to retinal vein occlusion. Ophthalmology 2010;117:11341146.

87 Fung AE: A novel sustained-release intravitreal drug delivery system for retinal vascular disease. Retina Today 2010;5:51-53.

88 Mohammad DA, Sweet BV, Elner SG: Retisert: is the new advance in treatment of uveitis a good one? Ann Pharmacother 2007;41: 449-454.

89 Mahajan VB, Gehrs KM, Goldstein DA, Fischer DH, Lopez JS, Folk JC: Management of sympathetic ophthalmia with the fluocinolone acetonide implant. Ophthalmology 2009; 116:552-557.

90 Callanan DG, Jaffe GJ, Martin DF, Pearson PA, Comstock TL: Treatment of posterior uveitis with a fluocinolone acetonide implant: three-year clinical trial results. Arch Ophthalmol 2008;126:1181-1201.

-91 Ramchandran RS, Fekrat S, Stinnett SS, Jaffe GJ: Fluocinolone acetonide sustained drug delivery device for chronic central retinal vein occlusion: 12-month results. Am J Ophthalmol 2008;146:285-291. 